\title{
AGRONEGÓcIO, PRODUÇÃO DE ALIMENTOS E SEGURANÇA ALIMENTAR NA AMÉRICA LATINA
}

\section{Solange Maria Gayoso da Costa}

Universidade Federal do Pará (UFPA)

\section{AGRONEGÓCIO, PRODUÇÃO DE ALIMENTOS E SEGURANÇA ALIMENTAR NA AMÉRICA LATINA}

Resumo: $O$ texto discute o agronegócio, modelo de produção agrícola amplamente alardeado como solução para o problema da fome no mundo, que, objetivamente, tem se mostrado altamente concentrador de terras e se constituído ameaça crescente a segurança e soberania alimentar, na medida em que contribui para a extinção das pequenas produções agrícolas responsáveis pela diversa produção de alimentos. Enfatiza que tal processo vem sucedendo há décadas em muitos países da América Latina e tem se expandido de forma acelerada e violenta provocando a desterritorialização de pequenos produtores, povos e comunidades tradicionais.

Palavras-chave: Agronegócio, concentração de terra,sojicultura.

\section{AGRIBUSINESS , FOOD PRODUCTION AND FOOD SECURITY IN LATIN AMERICA}

Abstract: The text discusses about agribusiness, agricultural production model widely touted as a solution to the problem of hunger in the world, which, has been proved as a highly concentrator land and a growing threat to food security and sovereignty, as it contributes to the extinction of small agricultural production responsible for diverse food production. This process has been happening for decades in many countries of Latin America and has expanded rapidly and violently causing the dispossession of small farmers, people and traditional communities.

Key words: agribusiness, land concentration, soybean production. 


\section{INTRODUÇÃO}

Dos setores do agronegócio, o agroalimentar se destaca, mundialmente, como um dos mais estruturados. Dentre as diversas transformações, a da reestruturação da produção alimentar, via integração vertical transnacional das cadeias produtivas, provoca aumento na oferta de produtos, viabilizada pelas estratégias da especialização produtiva de regiões em diversos países, do consórcio de empresas e da integração dos produtores ao mercado global.

Os argumentos explicativos para a ampliação do sistema agroalimentar baseiam-se numa propalada crise do setor de alimentos, pela qual se justificam as diversas estratégias usadas pelos agentes/agências do setor. $O$ aumento da demanda mundial de alimentos tem induzido o crescimento, por exemplo, da produção de soja em larga escala.

Estudos da Organização das Nações Unidas para Agricultura e Alimentação (FAO) indicam que o número de pessoas que padecem de fome crônica no mundo alcançou, em 2009, o montante de 1 bilhão de pessoas, podendo chegar a 9,2 bilhões em 2050. A FAO afirma que o desenvolvimento agrícola garante a segurança alimentar mundial e a demanda tem sido atendida, em parte, pela produção comercial de grãos, um dos setores mais evoluídos (ORGANIZACIÓN DE LAS NACIONES UNIDAS PARA LA AGRICULTURA Y LA ALIMENTACIÓN, 2009).

Para baratear os custos da produção e atender a demanda por alimentos, introduz-se a soja na alimentação dos animais, estimulada pelas empresas agroalimentares, que dominam o comércio mundial. Ligada, então, à expansão comercial da produção animal, intensiva e industrial, a soja passou a ser o investimento prioritário da agricultura de grãos.

A produção da soja começou a desenvolverse nos Estados Unidos, na metade dos anos 1930, incentivada pela corporação dos produtores americanos de soja (American Soybean Association), para conter a crise de superprodução do algodão e do milho. Foi, inicialmente, utilizada na produção de óleo e, posteriormente, na alimentação animal, tornandose imprescindível nessa atividade. A produção mundial de soja envolve uma rede complexa de agentes que agrega empresas multinacionais, agências estatais e não estatais, agroindústrias e produtores, dentre outros, distribuídos por diversos países.

Ana Célia Castro (2005) aponta que o sistema agroalimentar da soja agrega um conjunto de setores, dentre os quais a produção e o comércio de grãos, a produção de óleos vegetais e a produção de farelo. A produção de grãos e de farelo depende da base produtora de commodities em larga escala, cuja eficiência em custos é o principal fator da concorrência. Afirma a autora que a produção de soja é, claramente, um empreendimento de grandes grupos, e há, tanto no plano mundial, como no caso brasileiro, tendência à concentração de capitais.

O sistema agroalimentar, registrado nas últimas décadas do século $X X$ e primeiras do século $X X I$, aprofunda ainda mais o padrão de ocupação e controle do território historicamente construído pela promoção e ação do Estado na difusão do modelo de concentração de terras gerando latifúndios. A inovação desse padrão está na mudança dos principais agentes econômicos que passaram a ter o controle estratégico do agronegócio. Se antes grupos empresariais locais assumiam essa condição, hoje são os grupos empresarias internacionais que detém o planejamento estratégico da atividade. Isso significa maior fragilidade para a economia local/ regional que nem sempre tem suas particularidades levadas em consideração, resultando, muitas das vezes, em conflitos em que as maiores perdas ficam com os agentes mais frágeis envolvidos no processo - principalmente pequenos agricultores, povos e comunidades tradicionais.

Esse modelo de produção agrícola amplamente alardeado como solução para o problema da fome no mundo tem se mostrado altamente concentrado de terras e potencial para aumento da insegurança alimentar, uma vez que, contribui para a extinção das pequenas produções agrícolas responsáveis pela diversa produção de alimentos. De fato, nos últimos anos, contata-se que a concentração de terras é um fenômeno mundial, até naqueles países em que supúnhamos que os programas de reforma agrária, implementados no século $X X$, tivessem acabado com ela. Em todos os países em que o agronegócio tem se instalado e expandido o controle da terra está sendo usurpado dos pequenos agricultores e, em muitos casos, sendo assumido por grandes corporações mundiais (GRAIN, 2014).

Em estudo recente, realizado pela organização, GRAIN (2014) identificou-se que as pequenas propriedades agrícolas ocupam menos de uma quarta parte de toda a terra agrícola do mundo; que a porção de terras na mão dos pequenos agricultores é cada vez menor e se essa tendência persistir a segurança alimentar está em risco. Outras constatações, identificadas pela pesquisa, indicam que o tamanho das pequenas propriedades está cada vez menor; que em conjunto as pequenas propriedades são mais produtivas que as grandes propriedades, contudo observa-se em vários países a sua diminuição, assim como, a do número de pequenos agricultores.

Uma tendência mundial que vem se consolidando nas últimas décadas, em que a expansão do agronegócio cresce, é o crescimento da concentração de terras. E na medida em que 
aumenta o volume de terras agrícolas nas mãos de poucos, cresce o número de pessoas passando fome. No presente artigo procura-se refletir sobre essa tendência tomando como referência a produção de soja na América Latina.

\section{AGRONEGÓCIO E CONCENTRAÇÃO DE TERRAS AGRÍCOLAS}

O processo de concentração de terras, consolidado mundialmente nas últimas décadas, tem provocado mudanças estruturais na atividade agrícola. Os investimentos nesse modelo de produção de monocultura destinada a exportação, gera efeitos devastadores na produção agrícola de base familiar voltada aos mercados nacionais e regionais afetando diretamente a oferta de alimentos. Pesquisa realizada pela organização GRAIN (2014) sobre a concentração de terras explicita bem essa situação em que mais de $90 \%$ dos agricultores do mundo são pequenos agricultores e/ou indígenas, entretanto controlam apenas um quarto da terra agrícola mundial. Na Tabela 1 é possível verificar esses dados.

A pesquisa realizada pela GRAIN apontou ainda que as pequenas propriedades pertencentes aos pequenos agricultores e indígenas estão se tornando cada vez menores. É acelerado o processo de extinção de pequenas propriedades na medida em que o agronegócio cresce, até mesmo nos países em que a reforma agrária foi implementada. $\mathrm{Na}$ América Latina e Caribe $80.1 \%$ do total de propriedades são consideradas pequenas propriedades que estão na mão de pequenos agricultores e/ou indígenas, contudo ocupam apenas $19,3 \%$ de toda terra agrícola no continente. Em atenção ao proposto neste artigo destacamos os dados sobre a distribuição de terras nos quatro principais países latino-americanos produtores de soja - Argentina, Brasil, Bolívia e Paraguai (Tabela 2).

Pode-se observar na Tabela 2 que no
Brasil e Paraguai mais de $80 \%$ das propriedades são pequenas e ocupam $24.3 \%$ e $4.3 \%$ de todas as terras agrícolas respectivamente. A Bolívia se destaca por apresentar mais de $90 \%$ de suas terras sob a posse de pequenos agricultores/indígenas, entretanto respondem apenas por $47.5 \%$ das terras agrícolas. Na Argentina, observa-se índice menor que nos outros países, com $69.7 \%$ de propriedades nas mãos de pequenos agricultores, ocupando apenas $5.8 \%$ das terras agrícolas.

A diminuição do volume de terras nas mãos dos pequenos agricultores está diretamente ligada à rápida expansão das grandes propriedades voltadas especialmente à produção industrial. A conclusão que se chega é que mais e mais terras agrícolas férteis estão sendo ocupadas para produção de matérias primas destinadas a indústria agroalimentar e do agro combustível, pressionado os pequenos agricultores a ter menor participação na exploração da terra agrícola. O processo de expansão da sojicultura na América-Latina é representativo desse fenômeno.

3 A PRODUÇÃO DE SOJA EM PAÍSES LATINOAMERICANOS: os casos do Brasil, Argentina, Bolívia e Paraguai

A soja produzida atende duas grandes finalidades, $90 \%$ atende a demanda de produção de óleo e ração animal e os $10 \%$ restante é utilizado na semeadura ou processado em forma de grãos. Tradicionalmente, a soja é produzida em regiões temperadas e subtropicais, em diversos países, hoje é cultivada em regiões tropicais. O Brasil é o segundo maior produtor mundial, cerca de 96,2 milhões/t na safra 2014/15, atrás dos Estados Unidos da América (EUA) que produziu 106,9 milhões/t em 2014/15. Em terceiro lugar está a Argentina que chegou a produção de 61,4 milhões/t em 2014/15. Outros grandes produtores são China e Índia, mas com safras inteiramente voltadas para consumos internos.

Tabela 1 - Distribuição mundial da terra agrícola Terra agrícola (milhões de hectares

\begin{tabular}{|c|c|c|c|c|c|c|}
\hline & $\begin{array}{l}\text { Terra agrícola } \\
\text { (milhões de } \\
\text { hectares }\end{array}$ & $\begin{array}{l}\text { Número de } \\
\text { propriedades } \\
\text { (milhões) }\end{array}$ & $\begin{array}{l}\text { Número de } \\
\text { pequenas } \\
\text { propriedades } \\
\text { (milhões }\end{array}$ & $\begin{array}{l}\% \text { de } \\
\text { pequenas } \\
\text { propriedades } \\
\text { em relação ao } \\
\text { total }\end{array}$ & $\begin{array}{l}\text { Terra agrícola } \\
\text { em pequenas } \\
\text { propriedades } \\
\text { (milhões de } \\
\text { hectares) }\end{array}$ & $\begin{array}{l}\% \text { de terras } \\
\text { agrícolas em } \\
\text { pequenas } \\
\text { propriedades }\end{array}$ \\
\hline Asia-Pacífico & 1990.2 & 447.6 & 420.3 & $93.9 \%$ & 689.7 & $34.7 \%$ \\
\hline África & 1242.6 & 94.6 & 84.8 & $89.6 \%$ & 182.8 & $14,7 \%$ \\
\hline $\begin{array}{l}\text { América Latina } \\
\text { e Caribe }\end{array}$ & 894.3 & 22.3 & 17.9 & $80.1 \%$ & 172.7 & $19.3 \%$ \\
\hline $\begin{array}{l}\text { América do } \\
\text { Norte }\end{array}$ & 478.4 & 2.4 & 1.9 & $76.8 \%$ & 125.1 & $26.1 \%$ \\
\hline Europa & 474.5 & 42.0 & 37.2 & $88,5 \%$ & 82.3 & $17.4 \%$ \\
\hline Total & 5080.1 & 608.9 & 562.1 & $92.3 \%$ & 1252.6 & $24,7 \%$ \\
\hline
\end{tabular}

Fonte: GRAIN. Hambrientos de tierra: lospueblos indígenas y campesinos alimentanal mundo com menos de um cuarto de latierra agrícola mundial. Informe, Barcelona, maio 2014. Disponível em:<https://www.grain.org/es/article/entries/4956-hambrientos-detierra-los-pueblos-indigenas-y-campesinos-alimentan-al-mundo-con-menos-de-un-cuarto-de-la-tierra-agricola-mundial>. Acesso em: 8 jan. 2016 
Tabela 2 - Distribuição da terra agrícola em países latino-americanos produtores de soja - Argentina, Brasil, Bolívia e Paraguai

\begin{tabular}{|c|c|c|c|c|c|c|c|}
\hline & $\begin{array}{l}\text { Terra } \\
\text { agrícola } \\
\text { (milhões } \\
\text { de } \\
\text { hectares) }\end{array}$ & $\begin{array}{l}\text { Número de } \\
\text { propriedades } \\
\text { (milhões) }\end{array}$ & $\begin{array}{l}\text { Número de } \\
\text { pequenas } \\
\text { propriedades } \\
\text { (milhões) }\end{array}$ & $\begin{array}{l}\% \text { de } \\
\text { pequenas } \\
\text { propriedades } \\
\text { em relação } \\
\text { ao total }\end{array}$ & $\begin{array}{l}\text { Terra agrícola } \\
\text { em pequenas } \\
\text { propriedades } \\
\text { (milhões de } \\
\text { hectares) }\end{array}$ & $\begin{array}{l}\% \text { de terras } \\
\text { agrícolas em } \\
\text { pequenas } \\
\text { propriedades }\end{array}$ & $\begin{array}{l}\text { Îndice } \\
\text { de Gini }\end{array}$ \\
\hline Argentina & 174.808 & 297 & 207 & 69.7 & 10.099 & 5.8 & 0.83 \\
\hline Brasil & 329.941 & 5.175 & 4.368 & 84.4 & 80.250 & 24.3 & 0.87 \\
\hline Bolivia & 36.819 & 439 & 420 & 95,7 & 17.500 & 47.5 & - \\
\hline Paraguai & 31.087 & 290 & 242 & 83,4 & 1.340 & 4.3 & 0.99 \\
\hline
\end{tabular}

Fonte: (GRAIN, 2014).

Tabela 3 - USDA: projeções da exportação mundial de soja em grão - 2003/4 - 2014/15

\begin{tabular}{lrrrrrrrrrrrr}
\hline & $2003 /$ & $2004 /$ & $2005 /$ & $2006 /$ & $2007 /$ & $2008 /$ & $2009 /$ & $2010 /$ & $2011 /$ & $2012 /$ & $2013 /$ & $2014 I$ \\
& 2004 & 2005 & 2006 & 2007 & 2008 & 2009 & 2010 & 2011 & 2012 & 2013 & 2014 & 2015 \\
Arg & $\mathbf{6} 8$ & $\mathbf{7 , 7}$ & $\mathbf{7 , 1}$ & $\mathbf{7 , 2}$ & $\mathbf{7 , 3}$ & $\mathbf{7 , 3}$ & $\mathbf{7 , 2}$ & $\mathbf{7 , 2}$ & $\mathbf{7 , 2}$ & $\mathbf{7 , 1}$ & $\mathbf{6 , 9}$ & $\mathbf{6 , 7}$ \\
$\mathrm{Br}$ & 19,8 & 22,3 & 23,1 & 25,9 & $\mathbf{2 9 , 2}$ & $\mathbf{3 3 , 7}$ & $\mathbf{3 7 , 7}$ & $\mathbf{4 0 , 5}$ & $\mathbf{4 3 , 2}$ & $\mathbf{4 5 , 3}$ & $\mathbf{4 7 , 4}$ & $\mathbf{4 9 , 4}$ \\
EUA & $\mathbf{2 4 , 1}$ & $\mathbf{2 7 , 5}$ & $\mathbf{2 9 , 9}$ & $\mathbf{3 0 , 1}$ & $\mathbf{2 9 , 9}$ & $\mathbf{2 8 , 7}$ & $\mathbf{2 8 , 0}$ & $\mathbf{2 8 , 0}$ & $\mathbf{2 8 , 0}$ & $\mathbf{2 7 , 9}$ & $\mathbf{2 7 , 9}$ & $\mathbf{2 8 , 0}$ \\
China & 0,3 & 0,2 & 0,3 & 0,3 & 0,3 & 0,3 & 0,3 & 0,3 & 0,2 & 0,2 & 0,2 & 0,2 \\
Outros & 3,2 & 3,8 & 4,0 & 4,2 & 4,5 & 4,8 & 5,1 & 5,3 & 5,6 & 5,9 & 6,2 & 6,5 \\
América Sul & & & & & & & & & & & \\
Outros & 1,1 & 1,2 & 1,2 & 1,2 & 1,2 & 1,2 & 1,1 & 1,1 & 1,1 & 1,1 & 1,1 & 1,1 \\
Total & $\mathbf{5 5 , 3}$ & $\mathbf{6 2 , 7}$ & $\mathbf{6 5 , 6}$ & $\mathbf{6 9 , 0}$ & $\mathbf{7 2 , 4}$ & $\mathbf{7 5 , 9}$ & $\mathbf{7 9 , 4}$ & $\mathbf{8 2 , 4}$ & $\mathbf{8 5 , 3}$ & $\mathbf{8 7 , 6}$ & $\mathbf{8 9 , 9}$ & $\mathbf{9 2 , 0}$ \\
\hline
\end{tabular}

Fonte: USDA Agricultural Baseline Projections, apresentado em: BORGES, G. B. Brasil será o maior exportador de soja do mundo em 2014, diz relatório do USDA. Boletim Informativo, Curitiba, n. 853, fev./ mar. 2005.

Os EUA, o Brasil e a Argentina são os principais fornecedores de soja para o mercado mundial. As projeções do USDA Baseline Projections, sobre a comercialização mundial da soja em grãos, sinalizam que o Brasil apresentará crescimento exponencial, $54 \%$ das exportações mundiais em 2014/15

Tanto os EUAquanto a Argentina apresentam perda de fatia desse mercado conforme pode ser observado na Tabela 3.

Os três maiores produtores de soja Estados Unidos, Brasil e Argentina - respondem hoje por $80 \%$ de toda a produção mundial, com acelerada taxa exponencial, que em dez anos apresentou crescimento de $60 \%$.

Nos anos 1990, a produção norteamericana cresceu, em média, 4,15\% ao ano, enquanto que na América do Sul o ritmo de expansão foi de $17,45 \%$ ao ano. (LIMA, 2008, p. 54).

Dados da Organização Mundial do Comércio (OMC), em 2010, indicaram que o Brasil exportou

US\$ 61,4 bilhões em produtos agropecuários em 2008, comparados com US\$ 54 bilhões do Canadá. Em 2007, os canadenses mantinham estreita vantagem, com vendas de US\$ 48,7 bilhões, ante US\$ 48,3 bilhões do Brasil. (LANDIM, 2010).
A soja contribuiu para o aumento das exportações. Segundo dados da Secretaria de Comércio Exterior (SECEX) do Ministério da Indústria e Comércio Exterior (MDIC), a soja e derivados apresentaram expressivos crescimentos nas exportações na primeira década do século XXI. A introdução da soja no Brasil deu-se por volta do final do século XIX e início do século XX pela aquisição de material genético proveniente dos EUA. O plantio mais antigo, que se tem registro, data de 1882, na Bahia. Também no inicio do século XX, migrantes japoneses, com grãos trazidos em sua bagagem, iniciaram o cultivo em hortas domésticas no Estado de São Paulo para a produção de derivados, como o tofu, missô e o shoyu (HASSE, 1996; EMPRESA BRASILEIRA DE PESQUISA AGROPECUÁRIA, 2004; CASTRILON FERNANDEZ, 2007). A terceira região de inserção da soja foi o Estado do Rio Grande do Sul, base de difusão da produção no Brasil (HASSE, 1996).

Entre as décadas de 1940 e 1970, a produção de soja foi amplamente experimentada em pequenas e médias propriedades familiares de até 50 hectares na região sul do país. Com a adaptação da produção em áreas tropicais e com a inserção da região centro-oeste, ainda na década de 1960, passou para o cultivo em larga escala com a mecanização em propriedades que variam entre 300 a 10.000 hectares. Atualmente, no estado do Mato Groso, há cultivos em propriedades acima de 10.000 
hectares.

Atualmente, dezessete estados brasileiros aparecem nas estatísticas oficiais como produtores de soja. Do total da produção, 45,7\% concentrase na região Centro-Oeste; na região Sul 35\% da produção, na região Nordeste e Sudeste, respectivamente, $8,4 \%, 6,1 \%$ da produção brasileira e na região Norte $4,45 \%$. Observa-se na Tabela 4, que as regiões Centro-Sul agregam juntas $87,14 \%$, enquanto Norte/Nordeste figuram com percentual bem menor de $12,86 \%$. As áreas de cerrado e Amazônica são apontadas como espaços de expansão futura da monocultura da soja.

O processo de expansão da soja, no Brasil, é heterogêneo, apresentando maiores diferenças, principalmente, entre as regiões sul e norte do país. De um lado, a soja aparece atrelada à cultura de outros grãos, e de outro lado, vincula-se a um processo de exploração da madeira e da pecuária. Ao longo da década de 1980 (sec. XX), a soja ocupava as áreas de cerrado, tanto na região CentroOeste, nos estados de Goiás, Mato Grosso do Sul e Mato Grosso, como nos estados de Minas Gerais e Bahia. Já na metade da década de 1990 (sec. XX), verificou-se uma expansão da denominada fronteira agrícola, passando a desenvolver a produção nos Estados do Maranhão, Piauí e Tocantins, e nos estados de Rondônia, Amazonas, Pará e Roraima.

O crescimento da produção brasileira de soja e sua expansão geográfica reforçou a concentração de terras. Os dados dos censos agropecuários, de 1985, 1995 e 2006 (IBGE, 2006), revelam que enquanto a área ocupada pelos estabelecimentos rurais, com menos de 10 hectares, é menor que 2,7\%, da área total, a ocupada pelos estabelecimentos de mais de 1000 hectares, concentra mais de 43,0\%. Em números de estabelecimentos, a proporção altera-se radicalmente, maior percentual acima de $47,0 \%$ de número de imóveis, com menos de 10 hectares, enquanto os imóveis acima de 1000 hectares ficam em torno de $0,91 \%$.

A concentração de terras pode ser ainda verificada pelo Índice de Gini, que demonstra que, no período de 1995-96 a 2006, o Brasil apresenta alto grau de concentração, expresso por 0,856, em 1995, e 0,872, em 2006 (IBGE, 2006). A desigualdade na distribuição das terras tem sido a tônica no processo de modernização agrícola e na inserção do país no mercado mundial da soja.

Nesse cenário de concentração de terras, o censo populacional feito pelo IBGE aponta para a queda da população rural: em 2000 de 31.835.143, caí, em 2010, para 29.852.986. O número de pessoas ocupadas nos estabelecimentos rurais também é ilustrativo dessa queda. O pessoal ocupado nos estabelecimentos agropecuários, em 2006, foi de 16,5 milhões de pessoas, cerca de 1,3 milhão inferior ao registrado em 1996. Mesmo com menor percentual de áreas, os lotes inferiores a 200 hectares responderam por $84 \%$ das pessoas ocupadas nas propriedades rurais. Quase 12 milhões tiveram empregos temporários em 2006 de até 180 dias no ano. Esses dados reforçam afirmativa de que esse modelo de agronegócio é concentrador de terras e de rendas, em contraposição ao que apregoam as agências do agronegócio quando afirmam terem contribuído para a resolução da questão fundiária do país ao superar a estrutura agrária herdada do período colonial e a improdutividade da terra, ao colocar o latifúndio a serviço da produção gerando distribuição de riquezas e rendas.

Relatório publicado pelo Conselho Nacional de Segurança Alimentar do Brasil (CONSEA) (2010) apontou que o ritmo de crescimento da produção agrícola destinada a exportação é superior ao da produção de alimentos destinados ao consumo interno. No período 1990-2008, a produção de cana-de-açúcar cresceu $146 \%$ e a de soja, $200 \%$, enquanto o crescimento da produção de feijão foi de $55 \%$; de arroz, $63 \%$; e de trigo, $95 \%$. O aumento na produção dos monocultivos ocorreu não só pela expansão da fronteira agrícola, mas também pela incorporação de terras destinadas a produção de outros alimentos, conforme apontado no relatório:

Apenas quatro culturas de larga escala (milho, soja, cana e algodão) ocupavam, em 1990, quase o dobro da área total ocupada por outros 21

Tabela 4 - Soja no Brasil: produção por região safra 2014/15

\begin{tabular}{ccccc}
\hline REGIÃO & Área Plantada (em mil hectares) & \% Área & Produção em mil toneladas & \% Produção \\
\hline NORTE & 2499,3 & 4,4 & $4.289,5$ & 4,45 \\
NORDESTE & $8.143,6$ & 14 & $8.084,1$ & 8,4 \\
CENTRO-OESTE & $22.853,7$ & 39,4 & $43.968,6$ & 45,7 \\
SUDESTE & $5.104,4$ & 8,8 & $5.873,5$ & 6,10 \\
SUL & $19.395,2$ & 33,4 & $34.012,3$ & 35,35 \\
NORTE/NORDESTE & $10.642,9$ & 18,35 & $12.373,6$ & 12,86 \\
CENTRO-SUL & $47.353,3$ & 81,65 & $83.854,4$ & 87,14 \\
BRASIL & $57.996,2$ & 100 & $96.228,0$ & 100 \\
\hline
\end{tabular}

Fonte: COMPANHIANACIONALDEABSTECIMENTO. Soja - Brasil: safra 2014/2015. Brasília, DF, 2015. Série Histórica de Produtividade. Disponivel em:<http://www.conab.gov.br/conteudos.php?a=1252\&t=2\&Pagina_objcmsconteudos=3\#A objcmsconteudos> Acesso em: 8 jan. 2016 
cultivos. Entre 1990 e 2009, a distância entre a área plantada dos monocultivos e estas mesmas 21 culturas aumentou $125 \%$, sendo que a área plantada destas últimas retrocedeu em relação a 1990. (CONSELHO NACIONAL DE SEGURANÇA ALIMENTAR, 2010, p. 9).

Nos outros países da América-Latina podese observar o mesmo ocorrido no Brasil, inclusive com influência e participação decisiva deste país na expansão da sojicultura. Desde a década de 1970, observa-se a presença de produtores brasileiros, com domínio da tecnologia da produção agrícola mecanizada, em outros países da América Latina. Sojicultores migrantes, principalmente, os oriundos da região sul, foram responsáveis, por exemplo, pela ampliação das áreas de plantio de soja no Paraguai e na Bolívia.

No Paraguai, o agronegócio ganhou força na exportação sob o comando de empresas multinacionais, no final da década de 1960 e durante a década de 1970, com a migração de brasileiros sulistas sojicultores. Dentre esses brasileiros, está o agricultor Tranquilo Favero (70 anos de idade), um catarinense que chegou ao Paraguai há 40 anos, conhecido como o maior produtor individual de soja. Possui 45mil hectares de terras mecanizadas:

[...] o Paraguai tem 17 departamentos e em 13 deles eu tenho propriedades com soja, milho, trigo, canola, girassol, sorgo, com gado e com silos, 18 silos no total. (SOUZA, 2008)

Além de vender o que planta, o Grupo Favero (do qual Tranquilo é presidente), com 9 empresas, comercializa soja que compra de outros produtores. Segundo ele, entre $90 \%$ a $95 \%$ da soja no país está nas mãos de brasileiros (SOUZA, 2008).

Os resultados da expansão da sojicultura nos departamentos de Alto Paraná, norte de Itapúa e na parte oriental de Canindeyú, foi a expulsão dos agricultores paraguaios, a maior parte substituídos por brasileiros. O cultivo da soja, nas décadas de 1980 e 1990, atingiu cerca de 800 mil hectares (VILADESAU, 2008)

Na Bolívia, a soja, apesar de cultivada desde o ano de 1967, sua produção foi inexpressiva até o final da década de 1980, quando o Banco Mundial (BM) financiou o Projeto de Desenvolvimento das Planícies (Lowlands Development Project). Em decorrência desse programa, houve uma contínua expansão da agricultura mecanizada na região de Santa Cruz, alcançando uma área de cerca de $700.000 /$ ha até o ano de 2006. Produtores da região falam atualmente em 1 milhão de hectares: "[...] quando nós chegamos à área de soja na Bolívia era de 250 mil, 300 mil hectares. Hoje está em torno de 1 milhão de hectares." (Informação verbal) ${ }^{1}$. Atualmente, o agronegócio disputa terras inclusive com as denominadas Terras Comunitárias de Origem (TCOs), demarcações de áreas indígenas oriundas de uma lei agrária de 1996 (GIMENEZ, 2010).

Os produtores brasileiros, naqueles países, são responsáveis pela migração de tecnologia de produção, de variedades e pela implantação da infraestrutura. No Paraguai, construíram cidades como Naranjal, San Alberto e Naranjito e na Bolívia, a maioria mora na zona urbana de Santa Cruz de La Sierra, tem fazendas na região, implantaram estradas, construíram pontes e armazéns de grãos (CORRÊA, 2008).

O fluxo de produtores e empresas entre os países latino-americanos se intensificou. Assim como empresas brasileiras se instalam na Argentina, como o grupo AMAGGI, grupos empresariais argentinos também vieram para o Brasil, dentre os quais, o El Tejar, fundado em 1987 por produtores do interior da província de Bueno Aires, se estabeleceu no Mato Grosso há oito anos e produziu 673 mil toneladas de soja, na safra de 2010. Esse grupo possui 150 mil hectares de terras e arrenda um volume equivalente. O grupo atua ainda na Argentina, Uruguai e Bolívia (HENNEMANN, 2008).

Outro grupo, Los Grobo, chegou ao Brasil em 2008 para cultivar terras no Mapito, agora avança no Centro-Oeste. E um terceiro grupo é a MSU, empresa familiar com origem na Província de Santa Fé, chegou ao Brasil em 2007 e já produz 73 mil toneladas de soja na Bahia e em Mato Grosso do Sul (HENNEMANN, 2008).

A exportação de tecnologia brasileira na produção de soja é iniciativa do governo brasileiro. A colaboração entre os países ocorre pelo intercâmbio de tecnologia para manejo e conservação do solo, controle biológico de pragas, inoculação de sementes, tecnologias para produção de sementes, plantio direto. A parceria incluiu ainda a capacitação de técnicos e produtores em tecnologias de produção e gestão em soja.

Assim como no Brasil, em outros países latinos americanos, observou-se a relação estreita entre o crescimento da produção de soja e a concentração de terras. A produção de soja na Argentina passou de 3,7 milhões de toneladas na safra de 1980-1981, para 10,8 milhões nos anos de 1990-1991 e 35 milhões em 2002-2003, ou seja, em cada dez anos a produção cresceu três vezes mais. Com o crescimento da soja, diminuiu a produção do girassol, do arroz, do algodão e de frutas, do número de cabeças do rebanho bovino e aumentou os impactos dos agrotóxicos para a fauna e flora. Identificou-se ainda, que o crescimento da sojicultura está relacionado ao desaparecimento das unidades de trabalho familiar, no período ente 1960-1988 fecharam 51 mil unidades agropecuárias e entre 1988 e 2002, 87 mil unidades, quase todas com menos de 200 hectares. Aqueles que ainda 
permanecem estão se submetendo às relações contratuais que o agronegócio impõe. (GIARRACCA; TEUBAL, 2008).

As empresas multinacionais dominam a organização do agronegócio argentino e juntas formam os chamados pools de siembra que transformam o setor agrícola num grande negócio (GIARRACCA; TEUBAL, 2008). Operam em todo o processo de produção, também induzindo a (re) organização do mercado de terras. Algumas compram terras, outras com contratistas arrendam as terras e provêm os maquinários, equipe e agrotóxicos. As empresas com seu poder econômico determinam a organização dos complexos agroindustriais em suas atividades antes da porteira, depois da porteira e induzem relações contratuais e sociais estabelecidas dentro da porteira.

Ao examinar os dados presentes nas estatísticas oficiais e nas pesquisas realizadas é seguro sinalizar que a produção de soja mecanizada, em grande escala baseada na utilização de grandes extensões de terras, com uso de alta tecnologia, volume alto de agrotóxicos e pouca mão-de-obra, tem se mostrado com alto grau de concentração de terras, o que implica na expropriação de pequenos produtores. Ou seja, a modernização da agricultura, nas últimas décadas do século $X X$ e primeiras do século XXI, reforçou ainda mais a concentração de terras e capital, gerando um excedente social e aumentando a insegurança alimentar.

\section{CONCLUSÃO}

O triunfalismo do agronegócio na imposição de um modelo de produção de matéria prima voltada a exportação, as commodities agrícolas, impõe uma reformulação do uso da terra. Por tratar-se de um modelo de produção que necessita de grandes extensões de terras, esta precisa ser assegurada de qualquer forma, eliminando todos os obstáculos, incluindo os pequenos agricultores, povos indígenas e comunidades tradicionais, expulsos de suas terras ou incorporando-os na atividade produtiva, provocando intenso processo de desterritorialização². O resultado imediato é a concentração de terras, desaparecimento ou encolhimento das pequenas propriedades agrícolas e por consequência a diminuição na oferta de alimentos.

De fato constata-se que o crescimento do agronegócio se traduz numa clara ameaça a segurança e soberania alimentar do mundo, pois, em muitos países, há regiões inteiras em que se observa apenas uma espécie plantada como a soja, a canade-açúcar, eucalipto, a acácia, etc. Soma-se a isso o intenso uso de agrotóxico e espécies transgênicas que apresentam risco à saúde humana.

Tal processo é facilitado pelo fato do Estado apresentar uma efetiva incapacidade de regular os fins sociais, econômicos e ambientais do acesso a terra e a produção de commodities agrícolas. A falta de regulação e controle, principalmente sobre as terras públicas, criam condições e facilidades à usurpação do direito à terra, daqueles que nela habitam já muitos anos, estimulando à sua apropriação e facilitando a incorporação ao agronegócio. Agrega-se o próprio envolvimento direto do Estado em potencializar políticas agrícolas e financeiras favoráveis ao agronegócio, em detrimento de maiores investimentos em políticas agrícolas destinadas ao pequeno produtor e diversificação da produção de alimentos.

\section{REFERÊNCIAS}

ALMEIDA, A. W. B. Agroestratégias e desterritorialização: direitos territoriais e étnicos na mira dos estrategistas dos agronegócios. In: A. et al. Capitalismo globalizado e recursos territoriais: fronteiras da acumulação no Brasil contemporâneo. Rio de Janeiro: Lamparina, 2010. p 101-143.

BORGES, G. B. Brasil será o maior exportador de soja do mundo em 2014, diz relatório do USDA. Boletim Informativo, Curitiba, n. 853, fev./mar. 2005.

CASTRILON FERNANDÉZ, A. J. Do cerrado à Amazônia: as estruturas sociais da economia da soja em Mato Grosso. 2007. 262 f. Tese (Doutorado em Desenvolvimento Rural) - Universidade Federal do Rio Grande do Sul, Porto Alegre, 2007.

CASTRO, A. C. Localização e Identificação das empresas processadoras de soja, suas áreas de influência, preço e custo de transporte relacionados. Brasília, DF: WWF-Brasil, 2005.

COMPANHIA NACIONAL DE ABSTECIMENTO. Soja - Brasil: safra 2014/2015. Brasília, DF, 2015. Série Histórica de Produtividade. Disponível em:<http://www.conab.gov.br/conteudos. php $? a=1252 \& t=2 \&$ Pagina_objcmsconteudos=3\#A objcmsconteudos>. Acesso em: 8 jan. 2016.

CONSELHO NACIONAL DE SEGURANÇA ALIMENTAR. A segurança alimentar e nutricional e o direito humano à alimentação adequada no Brasil: indicadores e monitoramento da Constituição de 1988 até os dias atuais. Brasília, DF, 2010.

CORRÊA, A. Expansão agrícola modifica economia de países vizinhos. BBC Brasil.com, São Paulo, 2008. Disponível em:<http://www.bbc.co.uk/ portuguese/reporterbbc/story/2008/03/ printable 1080304_ams_paraguai_expansaoagricola_ ac.shtml>. Acesso em: 23 set. 2011. 
EMPRESA BRASILEIRA DE PESQUISA AGROPECUÁRIA. Tecnologia de produção de soja: região central do Brasil. Londrina, 2004.

GIARRACCA, N.; TEUBAL, M. Del desarrolo agroindustrial a la expansióndel agronegocio: el caso argentino. In: BERNADO, M. F. (Org.). Campesinato e agronegócio na América Latina: a questão agrária atual. São Paulo: Expressão Popular, 2008. p. 139-164.

GIMENEZ, H. M. Questão Agrária na Bolívia: o caso da presença brasileira no desenvolvimento do agronegócio da soja. In: ENCONTRO INTERNACIONAL DE ESTUDOS SOBRE A AMÉRICA LATINA, 1., 2010, Natal. Anais... Natal: UFRGN, 2010.

GRAIN. Hambrientos de tierra: lospueblos indígenas y campesinos alimentanal mundo com menos de um cuarto de latierra agrícola mundial. Informe, Barcelona, maio 2014. Disponível em:<https:// www.grain.org/es/article/entries/4956-hambrientosde-tierra-los-pueblos-indigenas-y-campesinosalimentan-al-mundo-con-menos-de-un-cuarto-de-latierra-agricola-mundial>. Acesso em: 8 jan. 2016.

HASSE, G. O Brasil da soja: abrindo fronteiras, semeando cidades. Porto Alegre: L\&PM, 1996.

HENNEMANN, G. Há um novo 'rei da soja': grupo argentino El Tejar, que se instalou em Mato Grosso há oito anos, colheu $17 \%$ mais que o brasileiro Eraí Maggi. Blairo vai plantar soja na Argentina. Folha de São Paulo, São Paulo, ago, 2008. Disponível em:<http://paginadoenock.com.br/home/ post/9500>. Acesso em: 10 out. 2011.

INSTITUTO BRASILEIRO DE GEOGRAFIA E ESTATÍSTICA. Censo agropecuário 2006. Rio de Janeiro, 2006.

LANDIM, R. Brasil já é o terceiro maior exportador agrícola do mundo. O Estado de São Paulo, São Paulo, mar. 2010. Não paginado. Economia. Disponível em:<http://www.estadao.com.br/noticias/ economia,brasil-ja-e-o-terceiro-maior-exportadoragricola-do-mundo,520500,0.htm>. Acesso em: 14 nov. 2011.

LIMA, M. do S. B. de. Políticas públicas e território: uma discussão sobre os determinantes da expansão da soja no sul do amazonas. 2008. 446 f. Tese (Doutoradoem Desenvolvimento, Agricultura e Sociedade), Universidade Federal Rural do Rio de Janeiro, Rio de Janeiro, 2008.

ORGANIZACIÓN DE LAS NACIONES UNIDAS PARA LA AGRICULTURA Y LA ALIMENTACIÓN. EI
Estado mundial de la agricultura y la alimentación. Roma, 2009.

SOUZA, M. M. Brasileiro é o rei da soja no Paraguai. Jornal Valor Econômico, [S. I.], 19 mar. 2008. Não paginado. Disponível em: <http://www.valoronline. com.br>. Acesso em: 24 set. 2011.

VILADESAU, T. P. El agronegócio de la soja em Paraguay: antecedents e impactos socials y econômicos. In: BERNADO, M. F. Org. Campesinato e agronegócio na América Latina: a questão agrária atual. São Paulo: Expressão Popular, 2008. p. $17-43$

\section{NOTAS}

1 Fala de Nilson Medina, paranaense que foi para Santa Cruz de La Sierra no início dos anos 90 e hoje é um dos maiores produtores de soja da Bolívia. (CORRÊA, 2008).

2 "O conjunto de medidas designadas como 'agroestratégias' que têm sido adotadas pelos interesses empresariais vinculados aos agronegócios para incorporar novas terras." (ALMEIDA, 2010, p. 102 grifo do autor).

\section{Solange Maria Gayoso da Costa}

Assistente Social

Doutora em Ciências Socioambientais pelo Programa de Pós-Graduação em Desenvolvimento Sustentável do Trópico Úmido (NAEA/UFPA)

Professora da Faculdade de Serviço Social e do Programa Pós-Graduação em Serviço Social (PPGSS) do Instituto de Ciências Sociais Aplicadas (ICSA) da

Universidade Federal do Pará (UFPA)

E-mail: solgayoso@ufpa.br

gayososol@yahoo.com.br

Universidade Federal do Pará - UFPA

Instituto de Ciências Sociais Aplicadas - Avenida Augusto Corrêa, 01 - Guamá

CEP: $66075-110$ 